\title{
TRANSACTIONS
}

OF THE

\section{SOCIETY OF TROPICAL MEDICINE AND HYGIENE.}

JANUARY, 1913.

Volume VI. No. 3.

Proceedings of a Meeting of the Society on Friday, December 20th, 1912. SiR WILLIAM LEISHMAN, F.R.S., President, in the Chair.

\author{
TYPHOID AND PARATYPHOID VACCINATION WITH LIVE \\ ATTENUATED VACCINES. MIXED VACCINES. \\ By ALDO CA.STELTANI, M.D., \\ Director, Government Clinic for Tropical Diseases, Colombo (Ceyton).
}

Antityphoid inoculation was introduced, as is well-known, in 1897 by Sir Almroth Wright, who in this way placed in our hands the most powerful weapon we have at the present time in the fight against enteric. The medical man practising, like myself, in a tropical country where typhoid is one of the most terrible scourges, can appreciate to the full extent the great practical importance of Sir ALMROTH WRIGHT's discovery; which will rank among those which are of lasting benefit to mankind.

Among the collaborators of Sir Almroth Wright, the name of Col. Sir DAYID SEMPLE must be mentioned, and among the more recent workel's Sir WILLIAM LimishMAN, to whom we owe the most useful modification in the preparation of WRIGH's's vaccine. Sir WiLLIAM 
LEISHMAN made the important observation that the lower the temperature at which the bacilli are killed the higher was the immunising power of the vaccine: hence this is now prepared by heating the cultures at $53^{\circ} \mathrm{C}$. instead of $65^{\circ} \mathrm{C}$, as formerly.

Major Harrison, Major Commos, Major Cummar, and many other officers of the Royal Army Medical Corps, have carried out much important experimental work on the subject. Interesting investigations have also been made by Henderson SMrry, Russetr, and many others.

About the same time as Wrigrt in Eingland, PFEIfFer, and later KorLe, carried out a somewhat similar work in Germany. These two observers used emulsions of typhoid bacilli grown on agar and killed by heat. Other vaccines which have been used are the nucleo-protoid vaccine of Lostru and GaLEorTI; the vaccine of SHris, the vaccine of Vricerr. All these vaccines are dead vaccines.

Live vaccines-Historical.-In 1901-1902, working in Bonn, under: Professor Kruse, on the subject of typhoid agglatinins and immune bodies, I noticed that rabbits were much more rapidy immunised by injecting subcutaneously living cultures, than dead ones. A single subcutaneous inoculation of one or two c.c. of living typhoid broth culture induced a degree of immunisation, to obtain which four, six, and even more inoculations of dead cultures were necessary. It is from that time that I have always been convinced in my mind that living viccines-provided their inocuity be demonstrated-are preferable to dead vaccines.

In 1904 in Ceylon I made my first researches in man with live attenuated vaccines, prepared by the method presently to be deseribed. I inoculated myself and fifteen of my laboratory attendants, servants and coolies who volunteered. In 1908 I published a short paper on the subject in local medical journals and in the Ceylon Medical Reports. In 1009 I published in the Centralblatt fur Bakteriologie an article in which I came to the conclusion that vaccination with live attenuated cultures was harmless, and was probably giving a higher degree of immunisation than dead vaccines. In that paper and in a communication at th Bombay Medical Congress (1909), I gave also the results of my exper ments on the subject of mixed vaccines.

In 1911 MeTCHNIKOFF and BesReDKA made the very importal discovery that chimpanzees could not be vaccinated against typhoid 
dead vaccines, while complete immunisation could be easily obtained by live vaccines. The vaccination with live vaccines was quite harmless, but the general reaction was rather severe. To prevent this severe reaction METCHNIKOFF and BESREDKA introduced a live sensitised vaccine, viz.: the living typhoid bacilli were sensitised by mixing them with horse typhoid immune serum. Metchnikoff and BesRedra have ased recently their sensitised living vaccine in man, in a few individuals, with good results, and ALCock has tried it on a large number of people, studying the action of the vaccine very completely and obtaining also very good results. A great advantage of this vaccine would be the almost complete absence of local and general reaction after inoculation. The only complication observed by Aucock was an abscess developing at the place of inoculation in a woman, but a traumatism from which she suffered may have had an indirect part in causing the abscess. From the pus the B. typhosus was isolated.

Method of preparation of attenuated live vaccines.-Tubes containing 10 c.c. of broth are each inoculated with two loopfuls of a forty-eight hours old agar culture of a non-virulent typhoid strain, which has been kept alive in the Ceylon laboratory for several years. The broth tubes are kept in the incubator at $35^{\circ} \mathrm{C}$. for 24 hours ; they are then placed in a water bath at a constant temperature between $49^{\circ} \mathrm{C}$. and $50^{\circ} \mathrm{C}$. for one hour; after which the vaccine is ready for use. It can be standardised by using WRICHT's blood method, films of course; or by making plates in the same manner as for counting the number of bacteria in a sample of water, either before the heating process or after; the vaccine must be diluted with sterile broth, or too many colonies will develop on the plates. It is interesting to note how little the number of germs varies if the same sized loopful is always used, if the tubes contain exactly 10 c.c. of broth, and if the tubes are kept at exactly the same temperature and incubated for exactly the same length of time. We all agree, I think, that exact methods of standardisation have not yet been found: fortunately, in practice, provided a certain sufficient minimum quantity of vaccine be inoculated, it does not matter very much, within certain reasonable limits, what dose is given. FRIEDBERGER has demonstrated in the lower animals that when a single dose is given-provided a minimum sufficient dose be injected-the degree of immunisation is the same as that obtained by a dose many times larger. 
Dose and method of vaccination.-For an adult I used to give ten minims the first time and twenty minims the second,-now that I standardise the vaccine by WRIGHT's method I give 500,000,000 the first inoculation, and double the dose the second inoculation. Thin individuals and young women receive a little less. Children I have never done, but I should advise half or one quarter of the adalt dose. The interval between the two inoculations is one week. The inoculation of the vaccine is followed by a local and general reaction, as is the case with dead vaccines; in some cases the reaction may perhaps be a little more marked. Three or four hours after inoculation, the region of the arm where the injection has been made becomes painful and red, and fever supervenes which does not last longer, as a rule, than 24 to 36 hours, and does not in most cases incapacitate one for work.

As I do not believe that the immunisation given by vaccines, dead or alive, lasts in man, very long, I generally advise people to be vaccinated once every two years, or even once a year.

Innocuity of live attenuated typhoid vaccine.-The objection to the use of live cultures for inoculation is that they may give rise to serious symptoms, and may possibly make typhoid carriers of the inoculated persons. MorgaN's experiments in rabbits are quoted to shew the danger of making typhoid carriers. Morgan, and previously Backstern (1891), Kexser, Doerr, and others have in fact succeeded in making rabbits typhoid carriers by using living typhoid cultures. MongAN, to attain this object, inoculated intravenously 5 c.c. of live virulent cultures. The result of MoRGan's interesting experiments do not apply, it seems to me, to the method of typhoid vaccination I am describing. First of all my vaccine is made with a non-virulent strain: secondly, it is attenuated by heating it to $50^{\circ} \mathrm{C}$. for one hour : thirdly, it is injected subcutaneously, and not intravenously: fourthly, the amount injected is, in proportion, enormously less. The injection of a dose of 5 c.c. into a rabbit, corresponds to an injection of a dose 25 times larger in man: no one would inject 4 ounces of live vaccine-or dead vaccine, for that matter-into the veins of a man. In my experience rabbits inoculated subcutaneously with one or two c.c. have never become carriers.

METCENIKOFF and BESREDKA have not found that chimpanzees inoculated with live non-attenuated cultures become carriers. But after all, the most important test is the human test; and this, in my 
experience, clearly shows that the attenuated vaccine is harmless, and does not produce typhoid carriers. Before using it on a fairly extensive scale, I inoculated, eight years ago (1904), myself and fifteen of my attendants, servants and coolies, who volunteered for the experiment: none of us experienced any severe symptom and none of us became a typhoid carrier ; and it is to be noted that at the time the vaccine was prepared by heating at $50^{\circ} \mathrm{C}$. virulent cultures of typhoid, and not avirulent ones, such as I use at present. In one case, after four days from the injection, a fever developed, which lasted five days; the microscopical examination of the hlood proved it to be of malarial origin.

The Director of the Ceylon Government Chemical Taboratory, Professor BRowning, kindly submitted himself to repeated inoculations of live (attenuated) typhoid vaccine, receiving each time at first 1 c.c. of it: later $1 \frac{1}{2}$ c.c. and 2 c.c. The first inoculation caused a little local reaction and a slight degree of fever ; the second, a week later, induced a slighter local and general reaction; the third, fouth and fifth inoculations, always given at a week's interval, were practically not followed by any reaction, either local or general. After the sixth and seventh the local reaction was more severe, and Professor: BrownINi experienced a general malaise for twenty-four hours but no fever. I then stopped the inoculations for three weeks, after which he had another: one, which did not give rise to any symptom. A couple of months later he was again inoculated at intervals of one or two weeks; during eighteen months he had altogether fifty-three inoculations. He remained always in perfect health, although twenty-four of the later injections consisted of 2 c.c. each, and were of mixed live vaccines, two parts typhoid, one part paratyphoid $A$, one part paratyphoid $B$. Local and general reactions during the later period were generally absent, extremely slight when present.

Comparison between the immunisation power of dead and live typhoid vaccines.-That in rabbits a higher degree of immunisation is obtained by live vaccines than dead ones there can be no doubt, as I have already stated previously. As regards higher animals, of the greatest importance is MetchnikofF and Besrenta's observation, that in chimpanzees the degree of immunisation obtained by dead vaccines is practically nil, while the inoculation of live cultures completely protects the animal from experimental typhoid fever. 
As regards the immunisation obtained in man by using live attenuated raccines, I must state at once that unfortunately I have not been able to study, day by day, the amount of protective substances produced in inoculated individuals, as done in such a thorough and scientific manner by Sir WILLIA LisishMAN and his co-workers in connection with WrIeHT's vaccine and its modifications, nor am $I$ in a position to give large and elaborate statistics. I an the first to regret it, but lack of time, owing to many rontine duties, prevented me from doing so. I hare, however, made a few experiments, inrestigating in several individuals the amount of agglutinins produced, aud, in a few, the opsonic index. Eight to ten dars after the first inoculation a certain amount of agghtinins appears in the blood, and the opsonic index is higher. The amount of agglutinins is rariable, but $I$ have never: observed a rery high agghtination limit. This is higher, according to my observations, than in persons inoculated with dead cultures. In fact, in Ceylon, it is only exceptionally that I have noted a high production of agglutinins in people inoculated with dead vaccines. I am well aware, of course, that this is not the experience at home.

Some observations on Professor Browning, who had altogether fiftythree inoculations, may be of interest. In him agglutinins began to appear in the blood ten days from the second injection $(1$ in 20 positive, 1 in 40 bacilli, immobilised but no clumps). Four days after the fourth inoculation the agglutination limit was 40 ; after the fifth inoculation the agglutination limit was only 20 ; and after the sixth and seventh, hardly 10. It increased again to 20 after the eighth inoculation. After the fifteenth it went up to 80 ; since then it has always varied between 20 and 40 .

Statistics.-For the reasons I have already stated, I am not in a position to shew any properly drawn up statistics; but the following rough data may be of interest.

Persons inoculated at various dates before February 1st, 1911, whom I have been able to follow. * Results during the period between February 1st, 1911, to March 31st, 1912, when I went on leare:-

* The total number of persons inoculated is of course very much larger (more than 2,000), but some people get transferred to other colonies, and passengers and tourists of whom I have inocnlated a great many, leave the Island after a very short time and cannot be traced. 


\begin{tabular}{|c|c|c|}
\hline Method of Vaccination. & $\begin{array}{l}\text { No. of persons } \\
\text { inoculated. }\end{array}$ & $\begin{array}{c}\text { Cases of Typhoid among the } \\
\text { inoculated. }\end{array}$ \\
\hline Both inoculations with clead vaccine & 350 & 4 cases no (leathl. \\
\hline Both inoculatious with live vaccine... & 294 & 1 case (no death). \\
\hline $\begin{array}{l}\text { First inoculation with dead raccine : } \\
\text { second with live vaccine } \quad \ldots\end{array}$ & 260 & 1 case (no death). \\
\hline
\end{tabular}

Keeping properties of the live attenuted vaccine-As regards the number of living germs present it is rather surprising to note that this does not vary much in countings made at different intervals during a period of five months, whether the vaccine is kept in the ice-box $\left(10^{\circ} \mathrm{C}\right.$. to $15^{\circ} \mathrm{C}$ ), or at the room's temperature (in Ceylon $28^{\circ} \mathrm{C}$ to $32^{\circ} \mathrm{C}$ ) This is shewn by the following experiments, which I did with the assistance of Mr. E. BUrGess, to whom I wish to express my thanks:-

(A) Typhoid broth cultures $\left(10\right.$ c.c.) : 18 hours at $37^{\circ}$ (.., followed by one hour in watel bath at $50^{\circ} \mathrm{C}$., after which the tubes wele sealed in flame and stored in ice-box $10^{\circ} \mathrm{C}$. to $15^{\circ} \mathrm{C}$.

Tubo 1. No. of colonies per loopful at time of sealing $\quad \ldots \quad 1283$

$$
\text { ," after } 14 \text { dass.. } \quad \ldots \quad 1181
$$

Tube 2. No. of colonies per loopful at time of sealing $\quad \ldots \quad 1461$

" after one month $\quad$.. 1300

Tube 3. No. of colonies per loopful at time of sealing $\ldots 1161$

$$
\text { , , after five months .. } 1008
$$

(B) Vaccines prepared as above, but in sealed tubes stored at room temperature $\left(28^{\circ} \mathrm{C}\right.$. to $32^{\circ} \mathrm{C}$. in Cevlon).

Tube 4. No. of colonies per loopful at time of sealing ... 1120

$$
\text { , after } 14 \text { dars... ... } 1050
$$

Tube 5. No. of colonies per: loopful at time of sealing $\quad \ldots \quad 1221$

$$
\text { , after two months ... } 1130
$$

From the above it will be seen that during storage there is an extremely small decrease of living germs. It is interesting to note that practically the same results are obtained with paratyphoid vaccines $A$ and $P$. Tt is to be noted that the sealed tubes were large ones, the 
ordinary test tubes. It remains to be seen whether the same results are obtained by using small 2 c.c. tubes.

Important points to investigate are also the following :-

1. Is the stored vaccine as rich in vaccinating substances as fresh vaccine?

2. Is the stored vaccine as harmless as the vaccine freshly prepared?

As regards question 1 , from the few experiments $I$ have made in rabbits, it would seem that the vaccinating power of the vaccine after two months' storage is good; and this, after all, is not surprising, considering that, as already remarked, the number of live germs present in live vaccine stored for two months is very little less than at the time of its preparation. As regards innocuity in rabbits, it does not give rise to any disturbance whatever; as regards its action in man, I have inoculated it in 10 persons who had volunteered, without having on the average, more severe reactions than when using freshly prepared vaccine.

tive attenuated cholera vaccine.-On this vaccine I will only say a few words. First of all it should be stated that a live cholera vaccine is no novelty. So long ago as 1885 FERRAN attempted a live cholera* vaccine.

I first tried preparing an attenuated live vaccine in the same manner as the attenuated typhoid vaccine, viz.: by asing broth cultures heated at $50^{\circ} \mathrm{C}$. The vaccine so prepared, however, was practically not a live vaccine, as each c.c. of it contained only on the average five living germs per c.c. I then prepared the vaccine by heating broth cultures at $45^{\circ} \mathrm{C}$. and $48^{\circ} \mathrm{C}$. for an hour. With this procedure a much larger number of living germs was retained. After many trials I now prepare the vaccine as follows: an emulsion is mate into 10 c.c. of pepton-water of two agar cultures 48 hours old, and this emulsion is heated at $48^{\circ} \mathrm{C}$. (vacc. No. 1), or $45^{\circ}$ C. (vace. No. 2) for one hour. This vaccine should be used soon after preparation, or at least a few days after, the germs being as a xule all dead within a month in the vaccine heated at $48^{\circ} \mathrm{C}$, and in two months in the vaccine heated at $45^{\circ} \mathrm{C}$. This dose is half c.c. the first time, and one c.c. a week later. The local and general reaction are much more severe than with the dead vaccine. There is fever and general malaise for 48 houls. After 8 to 10 days in most cases there is well-marked production of agglutinins. In fact we used the blood of one of the inoculated coolies for the diagnosis of vibrios found from 
suspected fæces. It is to be noted however, that in some individuals the production of agglutinins is very small, and even in the cases in which such production is well-marked it varies greatly; one day the agglutination limit being very high, a few days later very low.

Live attenuated dysentery vaccine.-The same method is used as the one described to obtain live attenuated typhoid vaccine, but broth cultures should never be used in the preparation of a dysentery vaccine, as even if killed at $55^{\circ} \mathrm{C}$. to $60^{\circ} \mathrm{C}$., they give rise to an extremely painful infiltration at the place of inoculation, as shewn by KRUSE, SHIGA, and myself. I use pepton-water cultures heated at $50^{\circ} \mathrm{C}$. of the SHIGAKRUSE bacillus, or a polyvalent vaccine, prepared with several varieties of the germ; but the experiments made being few, I am not in a position to say anything definite on such dysentery vaccines. Much further investigation is required.

\section{Mixed Vaccines.}

I demonstrated in 1901-2 (Zeit für. Hygiene, 1902) that by inoculating an animal with two different bacteria at the same time, the blood produced agglutinins and immune bodies for both, and that the amount of agglutinins and immune bodies for each germ was about the same as in the animals inoculated with one germ only. For example, inoculating a rabbit at the same time with $B$. typhosus and a bacillus pseudodysentericus No. 1 (KRUSE), the blood of the rabbit developed the same amount of agglutinin and immune bodies for the $B$. typhosus and B. pseudo-dysentericus, as control rabbits inoculated with typhoid only and control rabbits inoculated with pseudo-dysentery only.

I demonstrated that even inoculating a rabbit with three different micro-organisms (B. typhosus + B. pseudo-dysentericus No. 1 (KRUSE) + strain of $B$. coli communis) the amount of agglutinin and protective bodies elaborated for each germ was nearly the same as in animals respectively inoculated with one germ only. During the course of these experiments I was able to confium that when the immunisation is obtained by a single inoculation, provided the minimum dose sufficient to obtain the maximum immunisation be given, the amount of agglutinins and immune bodies elaborated by the inoculated animals is not in proportion to the amount of cultures injected. A series of rabbits inoculated with 2 c.c. of typhoid cultures will give the same average 
agglutination limit and the same amount of immune bodies as a series of rabbits inoculated with 4 c.c.

Since 1905 I have experimented with several mixed vaccines in man, of which the principal ones are a typhoid + paratyphoid A + paratyphoid $B$ vaccine, and a typhoid + dysentery (Kruse-SHICrA) + dysentery FixXNer vaccine. I will limit my remarks to the byphoid + paratyphoid A + paratyphoid B, but I may be allowed to note that anyone wishing to experiment with mixed dysentery vaccines should be careful always to use pepton-water cultures, as broth cultures of dysentery give rise to an extremely painful infiltration at the point of inoculation.

Mixed typhoid-paratyphoid racine.-The mixed raccines are either dead vaccines, the cultures being killed in the usual way by heating at $55^{\circ} \mathrm{C}$, or lire attenmated raccines by heating the cultures at $50^{\circ} \mathrm{C}$. for an hour.

Notes on the subject of mixed raccines may be found in my old publications in the Centr. fiir Bachteriologie (1909), in the transactions of the Bombay Medical Congress (1909), and in the Ceylon Medical Reports.

During recent years I have used rather extensively both the dead mixed vaceine and the live attenuated one. The preparation is simple: several tubes containing 10 c.c. of broth each are inoculated with two loopfuls of an agar culture of typhoid forty-eight honus old; other tubes with two looptuls of paratyphoid $B$, and others with two loopfuls of paratyphoid A. All the strains I use are non-virulent, but rich in antigen, as shewn by animal experiments. The inoculated tubes are kept for twenty-foul hours in the incubator at $35^{\circ} \mathrm{C}$. These cultures are heated in a water bath at $55^{\circ} \mathrm{C}$. (dead raccine) or $50^{\circ} \mathrm{C}$. (live attenuated vaceme) for one hour; they are then mixed together in certain proportions in sterile petri dishes-two tubes $(20$ c.c.) of trphoid, one tube (10 c.c.) of paratyphoid $B$, and one tube $(10$ c.c.) of paratyphoid $A$.

The mixed vaccine consists of two parts typhoid, one part paratyphoid $A$, and one part paratyphoid B. I used to give ten minims of the mixed vaccine at the first inoculation and twonty or more at the second. Now I standardise by counting the germs before mixing, and give the following doses:- The first dose which I give consists of 300,000 millions typhoid, 150,000 millions paratyphoid $\mathrm{A}$, 150,000 millions paratyphoid $\mathrm{B}$. 
At the second inoculation, one week later, a double dose is given, but much larger doses can be safely injected. In the case of mixed vaccines I always recommend a third inoculation a week after the second, and of the same or larger dose than the second.

I have used both the dead and the attenuated live mixed vaccines extensively, and can say that they are both harmless. I may point out that in the case of Professor BrownIng, who had fifty-three attenuated live vaccine inoculations of typhoid, the last twenty-four were of a live attenuated mixed typhoid + paratyphoid $A+$ paratyphoid $B$ vaccine.

The live mixed vaccine may occasionally give rise to a slightly more severe local and general reaction than the dead one. In rabbits these mixed vaccines induce- especially the live ones--a certain amount of protective substances for the three germs; but a fact worth noting, and which has also been noted by Major Cummins and Major Cumming in rabbits inoculated with paratyphoid $A$ only, is the small amount of specific glutinins often elaborated for $B$. paratyphosus $A$. In man, agglutinins for all three germs are elaborated, but it is to be remarked that the agglutination limits for $B$. paratyphosus $A$ is often small. In some cases the agglutinin present for $B$. paratyphosus $B$ were in larger amount than any other; but, as shewn by the absorption method, not all of the $B$. paratyphosus $B$ agglutinin was specific. The blood of Professor Browning, who had fifty-three typhoid inoculations, of which the last twenty-four were of a mixed typhoid + paratyphoid $A+$ paratyphoid $B$ vaccine, when I left shewed the following limits :B. typhosus, 40 ; B. paratyphosus B, 80; B.paratyphosus A, 20.

\section{CONCLUSIONS.}

1. The use of live attenuated vaccine prepared according to the method introduced by me in 1904, and published in 1909 (Centralblatt fiir Batteriologie) is harmless. In preparing the vaccine the strain used should be non-virulent, but rich in antigen, as found out by animal experiments.

2. Such vaccine in the lower animals, and probably in man too, gives rise to a higher degree of immunisation than obtainable with dead vaccines. It must be stated, however, that in my experience in man the immunisation obtained by two inoculations of this vaccine or any of the dead vaccines, is never complete; it is only partial. 
3. Cholera and dysentery attennated live vaccines can be obtained by using a somewhat similar method as that for preparing the typhoid vaccine; but for the dysentery vaccine pepton-water cultures and not broth cultures should be used, as these give rise to an extremely painful infiltration at the site of inoculation. Much further investigation is necessary on the subject of dysentery vaccination.

4. I have no personal experience of the sensitised live vaccine recently prepared by Metchnikoff and BesRedkA, but their results seem to be extremely good, as shewn by Atcock. The experimental work of these observers on live vaccines is of great importance, having demonstrated that chimpanzees can be rendered immune to typhoid fever only by the inocnlation of living vaccines, either sensitised or not sensitised.

5. Various mixed vaccines can be prepared, either dead or attenuated live vaccines. The inoculation of such vaccines is harmless, and apparently in the lower animals they induce a degree of pluri-immunisation, the blood-developing protective substances for each of the germs inoculated.

6. I am of opinion that in countries where paratyphoid $A$ and B are endemic besides typhoid, a mixed vaccine, typhoid + paratyphoid $A+$ paratyphoid $B$, should be used. If a live mixed vaccine should be objected to, a dead mixed vaccine can be used with satisfactory results. The inoculation of such vaccines as shewn by me since 1909 is harmless, and it is probable that it gives a certain degree of immunisation for all three infections.

REFERENCES.

1. ALCoCk. Lancet, 1912 .

2. CASTELLANI. Zeitschrift fü Hygiene und Infectionskrankheiten, 1901 and 1902. Centralbl. für Bakteriologie, etc. 1909. p. 92.

Transactions Bombay Medical Congress. 1909.

3. Cummins. Journal R.A.M.C. 1912.

4. Leishman. The Harben Lectures. 1910.

5. Metchnikoff and Besredk. Annales Institut Pastent. 1911.

6. Wright. Treatise on Anti-Typhoid Inoculation. London. 1904. Studies on Immmisation. London. 1909. 
Major W. S. Harrison, R.A.M.C.: I agree with Dr. Castellani that the nearer we approach to a living vaccine the more likely we are to obtain a solid immunity. 'There are, however', several practical difficulties In the way of using living vaccines; in the first place I do not quite know how, when you store a live vaccine, you are going to ensure that it will remain at the same strength. Dr. CAsteldan examined his vaccines from time to time, and he found they gave approximately the same number of colonies each time, but that does not account for the dead ones; the bacteria are continually dying in cultures.

I made an experiment some time ago with typhoid cultures, and with the particular strain which I used I got a larger number of colonies after 24 hours than at any subsequent period, although the culture was obviously very much denser. I attributed this to the fact that a large number of the bacteria had died and therefore the colonies were reduced in number's.

Another serious objection to the use of live vaccines, and I think the most serious, is that you cannot use an antiseptic. It is all very well to use live vaccines in a laboratory, in the hands of a shilled bacteriologist, but when you issue the vaccine for use outside the laboratory, you must endeavour to secure the greatest possible safety. We have all heard of the very serious accidents which have happened from time to time because of the issue of a vaccine which did not contain an antiseptic. There was the Muktowal accident in India, where every man who was inoculated with a certain phial of plague vaccine died of tetanus. Then again another case occurred in New York, where anti-diphtheritic serum used for prophylactic purposes gave tetanus to every child injected with it. In both these cases there was no preservative in the inoculated material. There was a similar accident in Manila, this time after the use of a living vaccine. Such cases as these put one very much on one's guard against the issue of any vaccine which does not contain sufficient preservative to secure that it shall run no rish of contamination after issue.

Dr. C. J. Martin: I should like to express my cordial agreement with you, $\mathrm{Mr}$. President, that this paper is a very valuable addition to the question of typhoid inoculation.

When I read of Dr. Castellani's methods some few year's ago, I imagined that after heating cultures to $50^{\circ} \mathrm{C}$. for an hour, a great 
majority of the organisms were dead ones, and that is the case with the culture we have been in the habit of using in my labolatory for disinfection experiments, which is kept at a low temperature, and only subcultures allowed to be in the incubator 24 hours. The experiments Dr. CAsteldani referred to were to see what really did happen. We took an old culture constantly living in the incubator. The number of bacteria at the end of an hom at $50^{\circ} \mathrm{C}$. was practically the same as at the beginning. The bacteria went on growing logarithmetically at a tremendous rate for 30 minutes. After that time they diminished. We started with 600 per c.c., they increased to approximately 3,000 in the 30 mimutes, coming down to 400 in 60 minutes.

There is no difference of opinion that the nearer we can approximate to the living vaccine the better. Living vaccines are better than dead ones. One dimger is the difficulty about preservatives, which is quite obvious, and to my mind a very serious one. There is another difficulty: when you are responsible for vaccinating people who do not want to be vaccinated, as although you may be quite certain that it is all right, there are always sone people who will contract typhoid shortly after vaccination, and that will be attributed to the vaceination. Immunity is probably not produced by the bacillus whilst living, and I have hopes, therefore, that one may leam more about what it is in the bacillus that is responsible for the immunity that is aroused. When we know more about that we may be able to imitate more nearly the better effect produced by the living bacillus.

One point in criticism of Dr. Castellan's paper. He has not given us any evidence of attenuation. I admit that they may not be killed, but $I$ do not see the proof that they are attennated. Before $I$ can admit that there is any attennation, it must be shewn that bacteria heated to $50^{\circ} \mathrm{C}$, and surviving are less vimlent than when you started. For all I know they may be more virulent. I am sure we all envy him the superb opportunities he has had in Colombo, especially in having a colleague so willing to be experimented upon.

The double-barrelled method of vaccination seems to have some good points in it, and I have no doubt, Sir, you will agree with me that if you were going to inoculate your comrades in the Army for active service, it would be very useful to put in a few strains of dysentery. You have only one "go" at them, and you may as well do the best you can while 
wou have the opportunity. Incidentally I might point out, if anybod. wishes to imitate Dr. Casteldani, it is of the utmost importance it aidhere scrupulously to the details of the experiments. People do no realise, I am sure, and I am afraid it will be a long time before they do so, the enormous inffuence which one degree makes in the matter 0 : killing typhoid. The temperature co-efficient is $16 \mathrm{per}$ degree. Twe degrees means two-and-a-half times as quickly, and ten degrees means 300 times as quickly. Further the minutest changes in reaction makes an enormous difference in the rate at which they are killed-changes in reaction that camnot be ascertained by the ordinary test paper. Thirdly, the strain of trphoid and its previons history will give yon totally different results.

Major S. Lrue Cumms : I came here to-night under an obligation to D1: Castellair for his splendid "absorption" test. I shall leave this evening under a still greater. This subject is of interest to us Axmy doctors especially. As to the question of heating or not heating : for service purposes, I must endorse Major Hamisox's remanks. We have to be very careful where soldiers are concened. The tendency in the service is to compromise between the highest efficiency on the one hand and the greatest number of men we can get immunised on the other. The great object of anti-typhoid vaccination is to get as many immunised persons as possible in the community. It is far better to have 90 per cent. of people with 80 per cent. of immunity, than 9 per cent. with 99 per cent. immunity, because yon have, with every increase of the number of immunised persons, a smaller armount of infection in the community. I do not think any acquired immunity is likely to protect against a large dose of virulent organisms. What we have to protect against is the dose that people get in the ordinary course of events.

I think the vaccine used in the Army has conferred a relatively enormous amount of protection, and quite justified its use on a large scale.

As to the question of mixed vaccines, I was particularly interested in What Dr. CASTERLANI said about the combined typhoid and paratyphoid vaccine. This is a subject of great importance in the Army, as if we were able to protect against all three bacteila it would be so very much better than protecting against one only. Speating theoretically it is 
quite correct to give three antigens at one time. There is one practical difficulty which occurs to me-that the total amount of antigen in a given single inoculation is limited by the amount of reaction you produce. We should like to give a larger dose than 1,500 million of $B$. typhosus, but if we did we should have so much reaction that few would come forward for inoculation. If a mixed vaccine is suggested, we must do one of two things-either keep the dose of $B$. typhosus what it now is and add an equal amount of $B$.paratyphosus $A$. to it, or diminish the amount of typhoid and put in a certain amount of paratyphoid in its place. Experiments lead us to suppose that the amount of paratyphoid A. necessary to produce immunity, will have to be larger than the dose of typhoid to produce a similar effect, so that in combining our: vaccines we may have to raise the total dose of bacterial body substance considerably.

I should be very glad to know whethex anyone here can tell us whether a doubling of the total antigen resulting from the mixture of two different organisms can be tolerated by the patient without increased reaction. That is a point we hope to work out later at the Royal Army Medical College. Dr. Casteluant, speaking of the increase in the doses of vaccines, suggested that 1 c.c. or 2 c.c. of typhoid culture, given to a rabbit, brought about the same immunity as 4 c.c. or 5 c.c. I think I understood that?

Dr. A. Castelitani: There is not much difference in the results you get after inoculating the rabbit with 2 c.c. or 4 c.c., provided the cultures are alive.

Major S. Lrue Cummins: I should imagine that the same would be the case with dead cultures in their large quantities, but what you have to get at is the practical dose that can be given to human beings. Some interesting experiments were published from the Lister Institute during last summer, which brought out the interesting fact that the immunity produced by increasing doses does not increase after you get to a certain point; but below a high limit there is a great difference between the immunity following a very small dose and a moderate one. So that the point which, to my mind, has to be decided with regard to mixed vaccines is, can we combine a dose of paratyphoid bacilli with the 
Tresent dose (1,500 million in two injections) of typhoid vaccine, thus toubling the total dose of antigen, or must we halve the dose of each 1.1\% 1 aixed raccines.

Dr. A. J. Chalmers: Perhaps I may be allowed to bring the discussion down to a lower level, i.e., to that of the general practitioner. I have worked with Dr. CASTELLANI, and I have seen a great deal of his work, and $\mathrm{I}$ have done a certain amount of practice in Colombo, where we have great difficulty in the diagnosis of typhoid fever, and in the diagnosis of the variety of typhoid fever, and we have found the absorption test to be of the greatest use. I am well acquainted with Dr. Cisteluan's inoculations in Professor Prownisg. Only on one occasion, so far as I know, was he inconvenienced; and as a rule he seemed to stand the inoculations extremely well.

I lived in Colombo, where there were typhoid and paratyphoid fevers. What was $T$ to advise my patients? Personally, I know Dr. Castel tani's work very well, and I have great faith in him, and I advised my patients to go to him for inoculation. I agree with one speaker that it is not suitable work for the general practitioner, and I am inclined to think that it is better for the general practitioner to send his patients to the expert for inoculation with these vaccines. The point about the diagnosis I also wish to enforce because uny own experience has been that it is very difficult to be sure what you are dealing with in Colombo, and Dr. Castelilaxi's methods have proved to be very useful.

I). Hindirson Gutri: I suppose there is general agreement that live raccines are more efficient than dead vaccines. One would be glad of more exact data on this point, but assuming it to be the case, at least two explanations occur to onc.

If you inject a living vaccine, the organisms may multiply in the body so that the actually effective dose is much higher than the nominal one. We know that with dead vaccines, the higher the dose, the greater up to a certain limit is the response; and it is conceivable that the greater efficiency of the living vaccine as compared, dose for dose, with a dead raceine is party due to the multiplication after injection. Dr. CAstzhLaxi seemed to indicate that the living vaccine ploduces a greater 
reaction than the dead. In his rabbits, 2 c.c. of broth culture produced the same reaction as 4 c.c., and as 2 c.c. is not so near the limiting dose of typhoid for a rabbit, the identity of reaction might be taken to point to some nultiplication occurring.

The other explanation is that in killing the organisms we alter chemically the antigen in some way. The ideal method is to extract the active substances from the organisms unchanged, but this has not been achieved satisfactorily yet, for typhoid. It is possible that the nechanism of extraction as it occurs in the body is of importance. Is it not possible to obtain the desired result by killing the bacilli ontside the body by the same mechanism as is employed in the body? If one were to kill the bacilli by fresh human serm before injection, the resulting products should closely resemble those produced in the body. I do not know that this method could be practised on a large scale, but it should give good results.

Dr. A. DIstaso: I must pont out, first of all, that I have not had any experience on this subject. As a matter of fact, there are many observations which establish the view that certain microbes can be injected living into the human body without danger.

I quote the work of HAFFKINE on living cholera vibrio vaccine, and lately of CHARLES NICOLLE, who injected intravenously living cholera vibrios.

METCHAIKOFE and BESREDKA injected men with living sensitised typhoid bacilli, and this evening we have heard from Dr. CAstertaAn that he has applied the vaccination with living attenuated typhoid bacilli in man.

It seems also well established that those kind of micro-organisms injected subcutaneously are harmless; on the contrary, with micrococcus melitensis it is not the same, because the man or the animal is easily infected with the subcutaneous injection.

In consequence of these facts we may infer that we have no right to speak of a general law, as certain authors would lead us to suppose.

Now, the experimental basis of vaccination, with subsequent immunity in the human being, was the work of Sir A. E. WRIGHT, to whom we are indebted for our scientific knowledge on this subject. He proved thut he had obtained a true immunity by this vaccination by injecting 
Iiving microbes into the body of a man who had received three doses of vaccine for the purpose of preventive vaccination, and without any ill effects.

Another observation is quoted by VIncent of a true immunity after vaccination. A laboratory attendant was injected with preventive vaccine; afterwards he swallowed pure culture of typhoid bacillus without any detriment to his health. Still, the living vaccines may be the best, but the problem of practical importance is to render those vaccines stable and inoffensive. We must establish the principles on which we intend to work-we must know what happens in the body, how the body will react, how the immunity will be established. Till that time we should be very cautious. We know really very little about the virulence of these microbes and the problems of immunity, though we presume to know so much.

In view of what I have said, I find Dr. Castellani's work very important for he started in his work on typhoid vaccine by attenuating the virulence of the microbes in the way which was adopted in the beautiful discovery of PAsTEur.

Dr. F. M. SAXDWith: This is a bacteriological evening, and I speak on this subject as the admiring colleague who injects with faith into his patients some of that which comes from a good laboratory. But I can also speak as a patient injected with raccines against various diseases, and I take this opportunity of acknowledging my gratitude to the bacteriologists who have now given us an anti-typhoid vaccine which does not often produce a reaction apparent to the patient. Those of us who were vaccinated at the time of the south African War will remember the fever and other unpleasant symptoms, besides a local reaction painful for two or three days.

In July, 1900, foul of us on our royage to Cape Town vaccinated oulselves, some forty nursing sister's, and about eighty civilian orderlies. The sister's submitted to a second inoculation, which was then not considered so obligatory as it is to-day, but most of the orderlies declined to have a second dose of discomfort.

To-day, vaccination against typhoid produces almost no reaction in the ordinary individual, and none of these distressing lesults take place. 
That is due to the improvement in the manufacture of the vaccines, and I hope some further improvements may take place.

I doubt whether the time will ever arrive when the practitioner or the bacteriologist will vaccinate at one sitting any individual against the five or six diseases he is likely to meet with when he goes to the tropics, and I rather wonder, for the sake of the individual patient, whether it would be of any great advantage. Sometimes one is asked by a bride going to India (for they marry first and ask advice afterwards) whether she should not be vaccinated against small-pox and typhoid fever. There may be no bacteriological reason why both these things should not be done at the same time. I have seen this done, and the patients not only survive but write grateful letters. But I do not think those present to-night could tell us it is quite free from possible danger, and I do not think we should play tricks with patients.

In the question of dysentery we are dealing with a very large group of diseases-a very much larger grcup than we have in typhoid infection. I an converted to the view that it is possible to introduce typhoid and paratyphoid vaccine simultaneously, but I donbt very much whether you will be able to introduce with our present knowledge, typhoid, paratyphoid, dysentery of various kinds, and possibly cholera.

Sir Havelock Charles: Personally I have but little to add to this discnssion. I desire to congratulate Dr. CASTELIANI on his valuable paper. The point regarding the diagnosis of typhoid and paratyphoid is of immense importance, yet the difficulties are great. It comes to this, that the only means of determining that a case is paratyphoid is the isolation of the bacillus from the blood or dejecta during life, and that dependence cannot be placed on serological observations in the diagnosis of paratyphoid, since they are beset with so many fallacies and sources of error.

Paratyphoid to me is a very interesting disease. Many years agowhen discussions were prevalent on the continuous fevers in India-some maintained that there were only malarial fevers and enteric fever. I was with those who said you had these and also another, which was neither malarial nor enteric. That fever is now called paratyphoid. I was the victim of a bad attack, and two distinguished physicians said I had enteric. Against their diagnosis I emphatically protested, and when the 
critical period-about the fourteentls day-arrived, I said, "I will prove my contention," and took a violent purge. Improvement shewed I was right-that the fever was the kind that had then no name!

I think the study of statistics in India shews the great benefit that has accrued from inoculation against enteric, whilst at the same time it gives no protection against paratyphoid. This in spite of their very close clinical resemblances. But the micro-organisms differ, and the bill of mortality very materially differs in the two diseases. Dr. SANDwith, as usual, speaks practically in referring to inoculation $v$. enteric and revaccination of people going to the tropics. Both steps should be carried zut previous to departure.

Regarding inoculation against dysentery and kindred evils, really, this makes life a nightmare! Is it not better to strengthen the power of esistance and teach the man to take care of his body? If he leans on inoculations he will eat filth and drink filth. Let him observe cleanlizess in all things. Take only what comes from the fire, and avoid food und drink soiled by flies and dust and abominations. The fire cleanseth. The rule for the guidance of my household in India was ever- - the only lrink, boiled water; the only food, that direct from the fire. All food eaving the table was thrown away. It never came back again, for the eason that, no matter what precautions yon take, you can never be sure. 3ut the fire sterilises your food, your drink, your bread, your table ervice. In this lies safety and peace of mind during epidemics.

This is a bacteriological evening. My apologies are due for interrening with the heretical still small voice of practical experience.

Fleet-Surgeon P. W. BasseTt-Smith : There is just one point raised iy Dr. Castellani which has not been brought to the criticism of the neeting, and it is one of very great practical importance. In the Navy, f one has to recommend the living vaccines for a disease which may or nay not be very prevalent, one has to give very good reasons that there s no danger in the use of them. Dr. Casteldani mentions that in njections in rabbits in some instances carriers were produced. In his wn experiments he says that his results have been highly satisfactoryto carriers. Before we could really recommend the method we must lave stronger grounds for proving there was, in so doing, no danger to hose who are living together with the injected individuals. In a large 
community like rou have on board ships, or in naval barracks where there are so many men, if you should introduce living carriers by giving living typhoid vaccines, then the method is hardly advisable. We want further proof on that point before such measures would be recommended.

Sir W. Lersmax: I am extremely pleased to have heard this valuable paper, which is full of suggestions, and I am looking forward to seeing it in print, so that we may ntilise these suggestions in on typhoid vaccination work. The subject of living vaccines as against dead vaccines is of the very first importance. I agree with other bacteriologists who have spoken that a living vaccine is probably the ideal vaccine, but I do not think it has yet made its proofs. The proofs from animal experiments, I am personally a little sceptical about, although that may sound strange as we have so largely used them, but we have also done much analytical work with man, and we have ample human statistics of protection to set alongside this. One of the most important of the objections to living vaccine seems to me to be the danger of which Major HARRISON and others have spoken in sending it out into the world. It would be all very well if you could get the individual inoculated in your laboratory, but if you have to send out vaccine to out-stations and distant countries, I think there are great chances of danger. Dr. Martrs has pointed out that Dr. CASTELtaAi has not given sufficient evidence of attenuation or loss of virulence in his strain, and one can quite conceive a danger of infecting either a water supply or an individnal. That is a danger which we cannot afford to risk in the Army. Again, if we employed living vaccine for the soldiers, the fact would soon become generally known, and I am certain that it would raise violent popular objection to the inoculations. It has taken us years to get inoculation with dead raccine up to the present high standard of acceptance amongst the soldiers, and if it became known that we were inoculating with living vaccines, we should have to fight it all over again from the beginning, even if we had stronger evidence of its superiority than exists at present. I am also not yet altogether satisfied that a living vaccine is free from the danger of producing typhoid carriers; that can only be proved after a much larger experience than is on record.

Major Cumms has spoken on the very important question of mixed vaccines, which are occupying us very much in our laboratory. We now 
Tare enteric ferer prettr well under control in Indin: the incilence fals Iorer every year, and this, I am convinced, is largely due to the increased use of dead typhoid raccine, with which 80 per cent. of the British roops have been inoculated; but paratyphoid fever appears to be ncreasing. Whether this increase is a true increase I am not quite certain, because of the great improvement in our methods of diagnosis so that the true nature of these cases is detected more frequently, but it eanses a considerable amount of incapacity among the soldiers, and is a problem we have to meet. I see no reason why we should not eventually obtain an efficient mixed vacine, and $\mathrm{I}$ do not share Di. SANDwra's pessimistic views on this subject. I think the time may come when we shall be giving mixed raccines for three or: four different bacteral diseases, and letting our solliers go into the tropics immunised against plague, choleza, trphoid, and drsentery.

I should like to add one other crestion to the number which have been asked of Dr. Cistelthir, whether he has had any experience, personally or otherwise, of the treatment of trphoid patients with his living trphoid vaccine? That seems to mo a possibility, and $I$ do not see why it should not give oxcellent results.

Sir HAvenock Charezs was rathel severe upun bitcteriologists, and I am afraid I cannot agree with him in his position that we should not racomate peoplo lest imagining themselves secure, they should bo led to abandon other precations. Sir Haverock also thonght that cooker plague and cholera germs might bo a wholesome addition to one's diet. I know some officers who aided us in ont cxperimental work by swallowing sterilised cultures, and I should like to introntuce them to Sir HAverock, that they might relate to him their whappy memories.

Dr. A. Castetiani: I wish to thank Major Harison for his kind remarks. I agree with him that there are some practical difficulties in using live attenuated typhoid vaccines. I think that at the present time vaccination with attennater live raccines should be camied ont only in proper bacteriological institutes. As a rule, I use raccines freshly prepared.

Dr. MARMr's observations are of great interest. It was most interesting to find ont that certain strains multiply in increasing numbers during the first half-hour when kept at $50^{\circ} \mathrm{C}$. Dr. Martin asked me 
whether I an certain that the typhoid vaceine prepared according to my method is really attenuated, and whether there is any reason to believe that by keeping the cultures at $50^{\circ} \mathrm{C}$. for an hour the virulence of the germ is decreased. I admit we always talk about attenuating cultures and viruses by heat, and we are apt to do fewer experiments than we ought to do. I think that the vaccine is attenuated because neither in the lower animals nor in man it produces any serious symptom. Moreover, the growth on agar is not so abundant, but this, may probably be dne to the less number of living bacteria present. Professor Browning, as mentioned by Dr. CHaLMers, had fifty-three injections of this vaccine, and I could never see any serious symptom. Once, immediately after the injection, he went for a long motor drive, driving himself. An inflamed infiltrated patch developed at the place of inoculation, but it disappeared spontaneously in a few days.

I quite agree with Major Cummiss that the dose of mixed vaceine to be given should be fully studied.

Dr. Henderson SMite thinks that the possibility of further growth in the tissues cannot be excluded, and therefore the possibility of making typhoid carriers of the inoculated people cannot be excluded. I must say that I have done a large number of inoculations with living attenuated vaccines. I have never seen the slightest local serious complication except in two cases, when there was a patch of infiltration which developed after twenty-four hours and remained about a week. I pricked the place with a syringe, and got a few drops of blood from the patches of infiltration, but never found the typhoid bacillus.

Dr. Distaso is in favour of live vaccines, and he states that the typhoid germ was recovered from the tissues of the chimpanzees injected with live vaccines by Metorniroff and BesRedra. I think Dr. Distaso is right. I had the opportunity of speaking to Professor MeTchnikorf recently, and he told me the same thing, but he was very emphatic in stating that the germ had never been found in the blood of the general circulation. In connection with this it may perhaps be of interest to point out that the sensitised vaccines do not exclude completely some local complication. According to Aucock, in a woman after inoculation an abscess developed, and in the pus the germ was found, but probably the abscess was indirectly caused by a traumatism the woman suffered, 
As regards Dr. Sandwith's remarks as to poli-vaccination, I quite aree with Sir. WILLIAM LEISHMAN that, in a more or less distant future, it will be possible. At the present time I do not advise a typhoiddysentery vaccination. Mixed vaccine, containing typhoid and a dysentery of various types, gives rise to a rather severe general and local inflammation. I may say that in my experience in the lower animals one cannot give an inoculation which contains more than three germs. Up to three germs, rabbits react fairly well, producing protective substances for all, and the general health is not much impaired, but if one injects four or five different kinds of bacteria, the rabbit as a rule wastes and dies after a few weeks, and very little or no protective substances are found.

We all agree with Sir HAveLock CHARLes that paratyphoid is comparatively frequent in India. In Ceylon we get both paratyphoid $B$ and $A$; in India, apparently, $A$ is much more frequently wet with than $B$; in Ceylon the reverse seems to be the case.

Fleet-Surgeon BASSETT-SMITH is right, from a practical point of view, in asking that further investigation should be carried out before this method of inoculation with live attenuated vaccine be introduced into the Navy, but I think a dead mixed vaccine, typhoid + paratyphoid B + paratyphoid A might be used in the Army and Navy.

Sir WrLliam Leishman's remarks are worth the most serious consideration, coming from one of the greatest authorities on vaccination. He points out the danger which there may be in making typhoid carriers of the persons inoculated. He refers to my first fifteen cases, and states with reason that they are too few to exclude the possibility of making carriers. I would point ont, however, that besides the first fifteen cases, I have later on investigated with negative result numbers of further cases, among whom Professor Browning, who had fifty-three injections.

Sir William Leishman's suggestion of treating typhoid with living attenuated vaccines is very interesting. I have not much experience of the treatment of typhoid by means of dead vaccines. I tried it in some cases, but I was not very favourably impressed. When I go back to Ceylon I think I will try the treatment again, both with dead and live vaccines. 
In conchusion, I should like to express again my thanks to the members of the Society for their kind remarks. I wish to say again how sorry I am that my work has not been more complete, but perhaps the results of some of these researches may be worthy of further study, and I hope some officer of that truly scientific body, the Royal Army Medical Corps, will further investigate the subject, at least, of mixed vaccines, which may be of practical importance. 

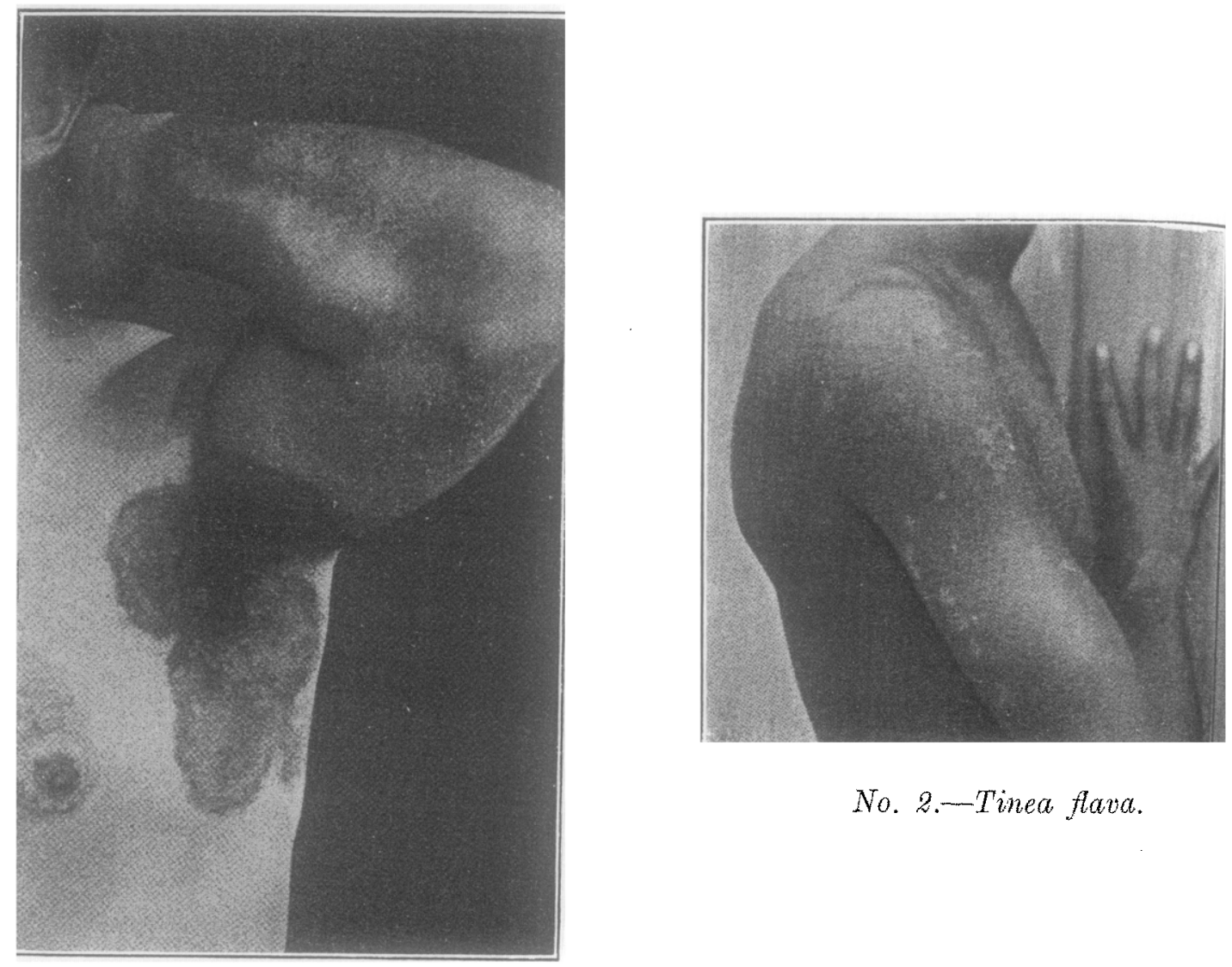

No. 2.-Tinea flava.

No. 1.-Tinea cruris. (Dhobie Itch).

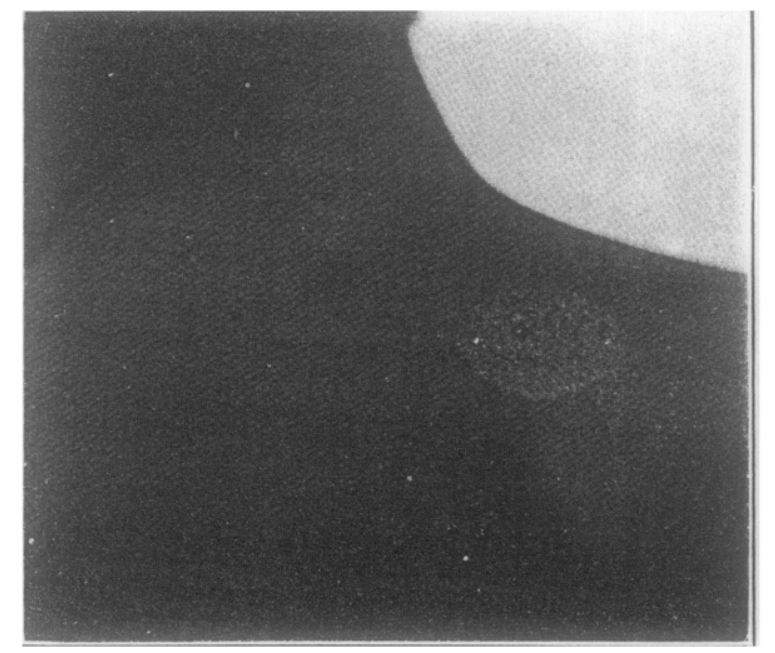

No. 3.-Tinea imbricata. (Experimental).

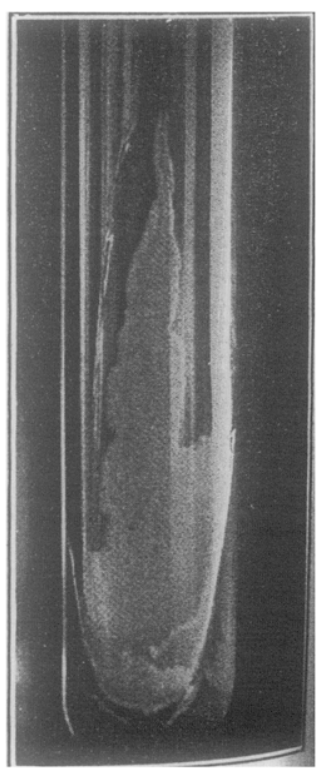

No. 4.- Monilia troply

ILLUSTRATIONS TO ACCOMPANY DR. CASTELLANIS PAPER. 